\title{
Characterisation of Innovations within the Multi-Level Perspective with Diffusion Typology of Innovations: A Fruitful Combination
}

\author{
Dorothee Keppler \\ keppler@ztg.tu-berlin.de | Technische Universität Berlin, Zentrum Technik und Gesellschaft, HBS 1, \\ Hardenbergstr. 16-18, 10623 Berlin, Germany
}

\begin{abstract}
This article seeks to show why and in which way a combination of the MLP with typology of innovations based on diffusion research can be fruitful for practical application of the MLP, as well as for refining the conceptual view on regime/niche interactions resulting from innovations from long established market niches. Application of the MLP to the example of absorption chiller innovations in the changing socio-technical refrigeration regime demonstrates that characterisation of innovations only by criteria offered by MLP authors can lead to inconclusive results. I argue that this is because they are innovations from market-niche technologies for which the distinction between radical and incremental innovations is not sufficient, as it neglects the changing character of innovations over time. It is important, I conclude, to clearly distinguish incremental innovations to market-niche technologies which perpetuate the radical character of their origin from incremental innovations of regime-dominant technologies. To enable a characterisation independent from the criterion of novelty that the MLP focuses on to distinguish radical and incremental innovations, I propose a more detailed classification based on theoretical and practical findings from diffusion research. Beyond facilitating a much more differentiated characterisation, this combination also opens up possibilities to reconsider and refine understanding of interdependencies of innovations from long established market-niche technologies and patterns of regime development.
\end{abstract}

Keywords. Technological innovation, Multi-level perspective, Socio-technical regime, Diffusion of innovation research, Energy efficiency

Cite paper as: Keppler, D., (2019). Characterisation of Innovations within the Multi-Level Perspective with Diffusion Typology of Innovations: A Fruitful Combination, Journal of Innovation Management, www.openjim.org, 7(2), 15-37. 


\section{Introduction}

At present, several supply or infrastructure systems are undergoing profound processes of change, from electricity or mobility to agricultural systems. The main challenge is to shape these processes in a way that creates more sustainable and climate-friendly system structures and mechanisms. In this context, the development and diffusion of sustainability-oriented innovations is a key element. As technology diffusion often requires and creates reconfigurations at the level of socio-technical systems and vice versa, systemic chance and innovation processes are strongly intertwined.

The multi-level perspective (MLP) has been frequently used to examine multiple fields of sustainable transition (Geels, 2007; Holtz, Brugnach \& Pahl-Wostl, 2008; Raven, Heiskanen, Lovio, Hodson \& Brohmann, 2007). Since this approach focuses on the interdependency of radical technological niche-innovations and socio-technical regime change, it is particularly suitable for fields of action where technology plays a significant role. One of the strengths of MLP is that it reflects the interdependency of technical and societal developments as well as of different levels of action, from innovations in socio-technical niches and pilot projects to national and international system levels.

Whereas the MLP approaches the issue of sustainability-oriented change primarily from the system perspective, diffusion theories approach the issue from the perspective of innovation. A wealth of research focuses on those factors which influence a broader dissemination of innovations that can contribute to more sustainable societal developments (Aizstrauta, Ginters \& Eroles, 2015; Dibra, 2015; Fichter \& Clausen, 2016; Karakaya, Hidalgo \& Nuur, 2014). Aside from characteristics of the technology itself, these research approaches consider a variety of societal aspects, from provider and adopter characteristics to policy and path-related factors (Clausen, Fichter \& Winter, 2011; Karnowski, 2017; Rogers, 2003).

This article discusses the positive effects of combining both the multi-level perspective and a classification of innovations based on empirical results from diffusion research. The example of absorption chiller innovations demonstrates why and in what ways this combination can be fruitful. In particular, I seek to demonstrate that

- the criterion of novelty the MLP uses for characterising radical and incremental innovations is insufficient at least in some cases

- this can be traced back to a disregard of the changing character of innovations over time, which is especially important for innovations having undergone long-term phases of stabilisation within market niches

- a combination of MLP and a more differentiated process of innovation typing based on diffusion-relevant criteria can enable a clearer classification of innovations independent from the state of regime/niche interaction at the time the characterisation takes place, and that

- this combination can also provide new ways to describe promising pathways of regime development.

Despite the known influence of innovations' characteristics on regime development, the relatively 
simple concept of innovations within the MLP, which distinguishes only between radical and incremental innovations and which characterises radical innovations by focusing on novelty as the central criterion for regime compatibility, has not yet been revised. And although the processoriented, diverse and long-term character of regime developments has been emphasised in the recent literature, consequences for the typing of innovations in different stages of regime and niche interaction have also not been considered within the framework.

Without question, this has proved to be an adequate approach for many cases as, in practice, relevant - radical - innovations are usually characterised on the basis of a public and/or scientific consensus that they can and probably will lead to a regime shift or because authors are engaging in retrospective analysis. In these cases a dedicated examination of the respective innovation's character may be dispensed with. The following will argue that this procedure is insufficient where no such clarity or consensus exists and where characteristics of the relevant innovation are equivocal. This will be illustrated with insights from the example of absorption chiller innovations in the field of refrigeration supply which, it is expected, will contribute to a more climate-friendly refrigeration supply regime. In this case, clear characterisation only by those criteria offered by the MLP has been hardly possible because incremental as well as radical qualities are featured. A closer investigation of the causes and possible solutions to this set of problems leads to the conclusions presented later.

This article is structured in the following way: section 2 presents the concept of socio-technical regimes and its extension to the multi-level perspective (2.1) and its current distinction between radical and incremental innovations (2.2). Based on this, section 3 then builds a socio-technical perspective on thermally driven cooling supply and current technical innovations in this field. As this attempt reveals that these exhibit characteristics of both incremental and radical innovations, I analyse underlying causes, focusing on the characteristics and function of market niches in the MLP innovations refining non-regime-dominant technologies (section 4), which has been neglected up to now. In order to address my findings, I suggest enhancing the distinction between radical and incremental innovations by using criteria from diffusion theory (5.1) and demonstrating the positive effects of this approach by applying it to the example of absorption chiller innovations (5.2), followed by a discussion in section 5.3. In section 6, I summarise essential results and draw some conclusions including the need for further research.

\section{The multi-level perspective}

\subsection{Socio-technical regimes and the multi-level perspective}

According to current definitions, socio-technical regimes can be characterised as heterogeneous and complex systems of coordinated and functionally coupled social and technical elements. A socio-technical regime includes a specific combination of physical artefacts, organisations, natural resources, scientific elements and legislative artefacts (Geels, 2002, p. 1257), allowing the system to provide a certain societal function (like water or electricity supply) (Holtz et al., 2008, p. 629; Kemp, 1996, p. 155; Kemp, Schot \& Hoogma, 1998, p. 182).

The socio-technical regime approach has its roots in Nelson and Winter's conception of technolo- 
gical regimes as well as in the conception of technological paradigms of Giovanni Dosi (cf. Kemp et al., 1998, pp. $176 \&$ 181). Compared with these older conceptions, however, which focused on technological properties and engineers' beliefs, the socio-technical regime approach has been broadened in two respects.

First, the research perspective has been enlarged from merely examining engineers' search heuristics and routines to a comprehensive consideration of multiple factors of technology development. Consequently, technological development paths are now held to be also shaped by existing technological designs and the alignment of a dominant technology with its particular socio-economic context, including for example production routines, producer-user relationships, accumulated knowledge, habits, abilities and skills, social norms, governmental rules or established consumer patterns and lifestyles (Geels, 2002, p. 1260; Holtz et al., 2008, p. 625; Kemp et al., 1998, pp. $177 \& 181-182)$.

Constitutive for the conception of socio-technical regimes is, second, a multi-actor perspective that supersedes the former focus on engineers or rather engineer-entrepreneur relationships. Technology development processes and technological trajectories within socio-technical regimes are also influenced by users, politicians, societal groups, scientists, capital companies and others (Geels, 2002, p. 1260, 2007, p. 128; Raven, 2005, p. 29). Actors' decisions and activities, their interactions with each other and with technology, are structured by system-specific formal, normative and cognitive rules (Geels, 2002, p. 1259, 2004, pp. 902-906, 2007, pp. 127-128; Kemp et al., 1998, p. 182; Raven, 2005, pp. 27-29).

Socio-technical regimes usually have two typical patterns of dynamics and change, in which two types of innovation play a central role: first, path dependent, incremental change in stable systems and second, radical change or socio-technical transitions, arising from radical innovations taking place within the context of unstable socio-technical regimes and landscapes (Geels, 2002, p. 1260).

Generally, socio-technical regimes are dynamically stable entities. The close interconnections of the elements within a regime enable smooth processes but also tend to discourage deviation from existing routines and development paths. Following existing trajectories, actors can profit from realised advantages of existing technology and matching social structures (like increased performance, established producer-user relationships or competencies). This is why dynamics in stable socio-technical systems usually follow existing trajectories and innovation activities are of an incremental nature, meaning especially improvements to existing technologies which do not threaten established trajectories. (Geels, 2002, pp. 1258-1259, 2004, p. 910, 2007, p. 128; Hoogma, Kemp, Shot, \& Truffer, 2002, pp. 155-156; Kemp et al., 1998, pp. 177-180 \& 183-184; Raven, 2005, pp. 29 \& 33)

Although the path dependency of a regime's dynamics constitutes a strong barrier to innovation, socio-technical regimes can undergo processes of radical change under certain circumstances, known as a socio-technical transition or regime shift. During this process, the material and social structures and rules of the existing socio-technical system are replaced by new ones (Geels, 2002, 2004, pp. 912-914, 2007, pp. 129-131; Holtz et al., 2008; Kemp et al., 1998; Rotmans, Kemp, \& van Asselt, 2001).

To provide a framework for addressing this issue, the multi-level perspective proposes a three-level 
model in which the two additional levels of socio-technical landscapes and niches complement the regime level. The central hypothesis holds that radical change is the result of the interplay between these levels (Geels, 2002, 2007, 2007, 2011; Geels \& Schot, 2007; Kemp et al., 1998; Kemp, Rip \& Schot, 2001). Viewed through this lens, a socio-technical regime becomes embedded in a socio-technical landscape, a set of deep structural trends including factors such as oil prices, economic growth, wars, emigration, broad political coalitions or cultural and normative values, and forming an overarching structure. Landscape factors usually stabilise socio-technical regimes and favour incremental changes along existing socio-technical pathways (Geels, 2002, 2004, p. 913; Rotmans et al., 2001, pp. 19-20).

Meanwhile, socio-technical niches are situated below the regime level. They are where radical innovations which are not viable within the selection mechanisms of the current regime find a protected space. Here, new technologies (as well as their associated networks of actors) and new rules can develop until they are robust enough to be able to compete with established technologies within a socio-technical regime (Geels, 2002, pp. 1260-1261, 2004, pp. 912-913, 2011, p. 27; Kemp et al., 1998, p. 184; Raven, 2005, pp. 31-32; Smith \& Raven, 2011).

Socio-technical niches are constituted by actors (research and development institutions, spin-off groups, social networks, governmental institutions) who believe in the future benefit and viability of a new technology. They are therefore prepared to invest resources in its development at a very early stage, when the technology is still immature, expensive and uncompetitive (Agnolucci \& McDowall, 2007, pp. 1395-1396; Geels, 2004, p. 912; Kemp, 1994, pp. 1034-1035; Raven, 2005, p. 31; Smith and Raven, 2011, pp. 3-8). On a material level, niches consist of local experiments, pilot or demonstration projects, in which involved actors can optimise and adapt a new technology to user demands in real-world environments. Niches also help to develop necessary institutional adaptations and changes as well as social rules and networks of producers, users and regulating institutions that can enable and support further development and diffusion of the new technology. (Geels, 2002, p. 1261, 2004, p. 912; Kemp et al., 2001; Raven, 2005, pp. 37-43; Rotmans et al., 2001, p. 19; Smith \& Raven, 2011, pp. 8-11)

Not every strong socio-technical niche leads, however, to large-scale regime changes. This requires the coincidence of strong, successful niche development and unstable, weak regime and landscape structures that constitute a window of opportunity. Such a situation occurs when the alignment and connection of regime elements are weakened by internal tensions. Changes at the landscape level can put pressure on an existing regime from outside, such as when public protest leads to new regulations or when sudden changes like environmental disasters occur (Geels, 2002, pp. 1261-1262, 2007, pp. 124-125 \& 130-131; Kemp et al., 1998, p. 184; Raven, 2005, pp. 3031; Rotmans et al., 2001, p. 20). Nevertheless, regime structures remain sufficiently robust in these phases to work against radical change. Consequently, radical change is generally seen as the result of numerous gradual, mutually influencing and cumulative changes over an extended period of time (Geels, 2002, p. 1272; Holtz et al., 2008, p. 623; Kemp et al., 1998, pp. 183-184; Rotmans et al., 2001, pp. 016 \& 018). 


\subsection{Distinction between radical and incremental innovations}

The differentiation between radical and incremental innovations and the focus on radical innovations is one of the basic fixed points of the MLP, as it is the foundation for the distinction "between innovations that proceed along an established trajectory and radical shifts to a new trajectory" (Geels, 2007, p. 126). With this, the MLP adopts the perhaps most popular differentiation from economic science (Garcia \& Calantone, 2002, p. 120; Hellström, 2007; Konrad \& Nill, 2001, p. 27). Seeking a definition in the economic literature, we find that these terms usually characterise the novelty of an innovation, meaning "the newness of the offering, i.e. a technology or process can be significantly or only marginally different from its predecessors" (Hellström, 2007, p. 150). Radical innovations feature major advances, whereas incremental innovations represent less extensive changes to existing products or systems and lead to smaller improvements (Konrad \& Nill, 2001, p. 28). A high degree of novelty is typical for radical innovations and is associated with "fundamental changes in new products that represent revolutionary changes in technology" (Yang, Chou, \& Chiu, 2014, p. 152). The relevance of radical innovations for larger changes has been widely discussed (Garcia \& Calantone, 2002, pp. 120-121; Hellström, 2007, pp. 149-150; Yang et al., 2014, p. 152).

The MLP itself closely links radicalness with the criterion of regime compatibility and the dependent variable of need for protection which are introduced as a consequence of their novelty. A mismatch of radical innovations with a given regime is due to their low performance, higher costs and lack of competitiveness with respect to established incumbent and therefore, cheaper technologies. This mismatch leads to a need for protection from the regime's structures, rules and selection mechanisms (Geels, 2002, pp. 1260-1261, 2004, p. 912; Konrad \& Nill, 2001, p. 32) Incremental innovations are characterised by only making smaller improvements to existing technologies which, at most, lead to very minor systemic adaptations that do not jeopardise existing trajectories. Due to their different needs for protection, the MLP attributes radical and incremental innovations to specific places of origin: as radical innovations are not yet viable within an existing regime, they arise and develop in the protected spaces of socio-technical niches, whereas incremental innovations develop on the regime level (ibid).

In practice, relevant - radical - innovations are usually characterised according to a public and/or scientific consensus that they can and will probably push a regime shift (socio-technical transition). The literature on the ongoing transition of the electricity regime is a good example (see e.g. Levidow \& Upham, 2017; Osunmuyiwa, Biermann, \& Kalfagianni, 2017; Wainstein \& Bumpus, 2016). In other cases, authors are dealing with analyses from a retrospective standpoint (e.g. Geels, 2002, 2007), so that the character of the respective innovation has long been clear.

In the following section I will demonstrate that this procedure is insufficient if such clarity or consensus does not exist and if characteristics of the relevant innovation are equivocal. The multitude of possible regime/niche developments implies that characterisation of innovations by the criterion of novelty (the focus of the MLP) may be problematic from case to case. I will illustrate this assumption with insights from the field of refrigeration supply. 


\section{Absorption chiller innovations within the socio-technical regime of refrigeration supply}

In the following, I apply the MLP to the cooling sector and absorption refrigeration technology innovations. Based on the framework presented in section 2.1, I sketch the current positioning of adsorption-type refrigeration systems within the socio-technical cold supply regime.

The following statements are the result of socio-technical research in a research project on absorption chillers which has been using the MLP as its theoretical basis. There were good reasons for taking this perspective, as it allows an integrative consideration of the different levels that needed to be analysed: the level of field tests and that of (currently changing) overall framework conditions influencing the future of absorption refrigeration. In order to make sure that known success factors of niche development could be taken as an adequate base for analysis, it was necessary to examine whether current absorption chiller innovations should be considered radical or not.

The specifications in this section are based on a wide-ranging literature research. Since research has generally focused on technical developments and market chances in the refrigeration sector, the following portrayals concentrate largely on these aspects.

\subsection{The cooling sector as a socio-technical regime}

Up to now, refrigeration has played a minor role in discussions, programmes and strategies regarding energy saving, not least because it accounts for a relatively small proportion of energy consumption in Germany and Europe. Nevertheless, around $14 \%$ of German power consumption is used for refrigeration, creating $5 \%$ of direct and indirect German greenhouse gas emissions (Heinrich et al., 2014, p. 24). A drastic increase in refrigeration demand is predicted for the future. Strong efforts towards achieving climate-friendly and more energy-efficient solutions are therefore of vital importance.

The refrigeration sector comprises a variety of so-called cross-sectional technologies, meaning that they are deployed in a huge number of fields of application in industry, commerce and private households. In Germany, for example, domestic cooling has the largest share $(34 \%$ in 2011), followed by building air conditioning (15\%), industrial refrigeration (14\%), supermarket refrigeration (12\%), food production (9\%), commercial refrigeration (8\%), and others (Heinrich et al., 2014, p. 25; Henning et al., 2012a, p. 162). In line with its multiple fields of application, purposes of use and usage requirements, a wide range of refrigeration technologies exists. The particular technology to be deployed depends on the type of cooling, required temperature levels, cold demand and its characteristics, and on available area and operating power (Clausen, 2007; Henning et al., 2012a, pp. 221-222).

Refrigeration technologies are distinguished according to their operating power: electrically driven compression cooling technology on the one hand and thermally driven refrigeration on the other, encompassing several technologies of which absorption chillers are one example (cf. Eicker, 2012, pp. 147-154; Henning et al., 2012a, pp. 207-208). 
Currently, compression refrigeration is the regime-dominant technology, which is established for all performance classes (Eicker, 2012, p. 147; Förster, 2013, p. 12; Henning et al., 2012a, p. 160).

There has long been an established worldwide supply structure for compression chillers, with Reichelt (2000, pp. 4-5) listing manufacturers from Sweden, Brazil, China, Japan, the United States, Korea and elsewhere. Main sales markets can be located in (South East) Asia, the United States, Japan and Europe (Clausen, 2007, pp. 8 \& 20; Eicker, 2012, p. 147).

Absorption-type refrigeration technology has the largest share of thermally driven refrigeration technologies by far (Berliner Energie Agentur, 2009, p. 11; Eicker, 2012, p. 149; Schindler, 2010, p. 62). Nevertheless, this amounts to only one percent of the cooling technologies currently used in Germany (units sold per year) and less than three percent worldwide (Schmid, 2011a). Consequently, absorption refrigeration technology can be characterised as a market-niche technology within the current refrigeration supply regime.

Thus far, absorption refrigeration has only been used in certain fields with specific preconditions and requirements in the medium- and large-scale performance range (from approx. $300 \mathrm{~kW}$ to the megawatt level). It has mainly been employed for commercial and industrial refrigeration with typically high refrigeration capacities (process cold or air conditioning), for example in breweries, refrigerated warehouses and other applications with high cold demand (Förster, 2013, p. 12; Jakob, 2012, p. 153; Schindler, 2010). The majority are high-temperature applications direct-fired with gas or oil or heated with steam or hot water (Eicker, 2011, 2012, p. 150; Förster, 2013; Henning et al., 2012a, p. 168; Schindler, 2010, p. 62). At the low-performance range, absorption chillers have only been on the market for a few years (Eicker, 2012, p. 152; Henning et al., 2012b, p. 160).

Absorption chillers are mostly produced by established manufacturers of compression cooling machines, for which absorption cooling is an additional business. There are also start-ups which have been more or less successful in the market up to now (Albers, Kühn, Petersen, \& Ziegler, 2011, p. 1856; Clausen, 2007; Eicker, 2012, p. 147; Jakob, 2012, p. 153).

All refrigeration technologies are experiencing growing markets (Clausen, 2007, p. 8; Davis, 2015). The market for air conditioning is rising especially rapidly, with world sales in 2011 being 13\% higher than in 2010 (Cox, 2012). The most rapid increases are taking place in developing countries with rising incomes and very warm regions such as India or China where sales have nearly doubled during the last few years (Davis, 2015; Sivak, 2013). However, the same trend is also occurring in Europe, though on a smaller scale (Eicker, 2011). Reasons are diverse, including the impact of climate change, rising demand for comfort, changing building designs and expanding demand in the commercial sector (Eicker, 2012, p. 147; Henning et al., 2012a, pp. 74-85 \& 118; Kranzl et al., 2014; Schmid, 2011b, p. 42).

Forecasts predict that the refrigeration sector is likely to continue growing substantially in the upcoming years (Clausen, 2014, pp. 2, 18 \& 20; Cox, 2012; Henning et al., 2012b, p. 191), with an estimated rise in the demand for air conditioning alone of 50\% between 2006 and 2020 (Berliner Energie Agentur, 2009, p. 27; Kranzl et al., 2014, p. 30; Petersen et al., 2013, p. 42).

In the context of climate change these developments are highly problematic and have been a 
crucial subject of European and national climate and energy policy. For example, German regulation of energy-efficient technologies and buildings fosters more energy-efficient cooling technologies and refrigeration systems by setting standards for the maximum energy consumption of buildings (Heinrich et al., 2014, p. 179; Henning et al., 2012c, pp. 66-82; Schmid, 2011a, p. 12, $2011 b$, p. 42). Several programmes provide financial incentives for energy-efficient investment or climate protection measures on refrigeration plants (BMWi, 2015; Henning et al., 2012c, pp. 24$27 \&$ 83-89). New funding programmes are promoting enhanced research and development, for example the German Energy-Optimised Building Construction programme (ENOB) or a funding programme for process cooling and heating within the energy research programme of the German federal government (Henning et al., 2012c, pp. 56-65). In addition, regulations on regenerative and energy-efficient power generation affect developments in the cooling sector, amongst others, by inducing rising prices for electricity, enlarging the availability of heat and power from renewable resources and/or the use of waste heat from industrial processes and heat from combined heat and power generation (Henning et al., 2012c, pp. 16-24 \& 38-43).

Due to these developments, researchers have been predicting and demanding a substantial rise in thermally driven refrigeration. This assessment has been nurtured by a new generation of absorption chillers (Albers et al., 2011; Clausen, 2014; Eicker, 2012; Förster, 2013; Petersen et al., 2013; Schindler, 2010). Expectations regarding their possible environmental benefits are based on primary energy savings being obtained through using heat instead of electricity as operating power, using free heat capacities during summer months and thereby considerably contributing towards decreasing summer peak loads in electricity nets (e.g. Becker, 2006/2007; Clausen, 2007, pp. 1, 7 \& 18; Dittmann, Dittman, Seifert, \& Wirths, 2014).

Summarising the above, absorption refrigeration is a long established market-niche technology with a small but growing market share within the socio-technical regime of refrigeration supply. Innovative types of absorption chillers are giving rise to positive expectations of a substantive contribution to a more climate-friendly, regenerative-based and energy-efficient cold supply. Researchers in this field are very optimistic, but their future role and impacts on the overall share of electrically and thermally driven cooling are at the moment difficult to predict.

\subsection{Characterisation of absorption chiller innovations by criteria the MLP offers}

As the MLP focuses especially on radical innovations in socio-technical niches and their interactions with a particular regime, a clear characterisation is important for finding out whether the niche level is relevant at all.

For one thing, these innovations are to be characterised as incremental. Absorption refrigeration technologies are not completely new but have already been established for a long time. The technology was first developed at the beginning of the 19th century and has been more or less continually refined (Xi, Luo \& Fraisse, 2007; Ziegler, 1997). Thus, recent innovations in this sector represent enhancements to an existing technology. Improvements are not significantly different from their predecessors nor fundamental changes in new products. Researchers 
have highlighted higher energy efficiency, lower operating temperatures, space requirements and costs.

By contrast, current innovations also exhibit characteristics the MLP approach assigns to radical innovations. Firstly, constructive enhancements with respect to existing absorption cooling technologies are marked by differences which are significant enough to support expectations that extended possibilities for application beyond existing market niches are likely to arise due, amongst others, to the potential of combining them with novel (low-temperature) heat sources. Current research promises that existing (technological) obstacles for broader use of this technology could be surmounted. Secondly, the present range and variety of promoted demonstration projects and field tests can be described as experiments which are in effect constructing a sociotechnical niche, meaning that current development activities are taking place within protected spaces, generated by public funding. This indicates that, thirdly, the benefit, added value, competitiveness, efficiency, energy effectiveness and so on of these new types of absorption chillers have not yet been sufficiently substantiated, so their chances to thrive in the market beyond existing niches are still unclear.

As a result of these contradictory tendencies, I propose that clear classification of absorption cooling technology innovations cannot be easily achieved. Even though absorption cooling innovations are anything but new, a smooth adaptation to the existing regime beyond the current market niches cannot be realistically expected.

This observation raises the question of how to identify and clarify underlying causes. As an attempt to explore this, in the following section I take a closer look at the current position of absorption refrigeration technology as a market niche within the existing regime. My assumption here is that this position is crucial for understanding the dual nature of current innovations in this domain.

\section{Reconsidering conceptions of "radical" and "incremental" for innovations from market niches within the MLP}

In the following, I reconsider the conception and location of market niches and of radical and incremental innovations within the MLP and examine whether the fact that innovative absorption chillers originate from a market-niche - and not from a regime-dominant - technology is important for understanding their characteristics.

Contributions from the literature dealing with the process-oriented nature of niche/regime interactions and their possible outcomes provide indications regarding how the MLP conceptualises niche markets, locating them in time between socio-technical niches and mainstream markets.

Market niches are described as being small and specialised. Unlike socio-technical niches, which are built around technological innovations by actors seeing a future potential in the technology, market niches are built around specific user-demand or performance-related attributes. Due to particular application contexts or consumer preferences, selection criteria are significantly different from the mainstream market (Agnolucci \& McDowall, 2007, pp. 1396-1397; Markard 
\& Truffer, 2008, pp. 605-606). As Markard and Truffer (2008, p. 605) propose, "Market niches $[\ldots]$ can be regarded as some kind of 'natural anomalies' in regimes".

Compared with socio-technical niches, market niches have a higher level of stability but offer lower protection, though they can offer some protection against the design and selection rules of a socio-technical regime (Raven, 2005, pp. $44 \& 47$ ). This applies if a niche market is protected or even created by technology policies in the form of subsidies or other financial resources, regulatory exemptions, expectations and strategic decisions (Raven et al., 2007, pp. 47-48). Public intervention usually takes place in order to "internalise unaccounted social benefits of a technology" (Agnolucci \& McDowall, 2007, p. 1397). To distinguish such niches from "regular" market niches, they are called "protected market niches" (Raven, 2005, p. 48).

Some in the literature have addressed variations in the interactions between socio-technical niches, regimes and landscapes, fanning out the linear consideration of the positioning of market niches within the MLP in time (Geels, 2002a; Geels and Schot, 2007; e.g. Konrad et al., 2004; Raven, 2005). Due to these contributions, refining the process from niche formation to different possible outcomes, the role or position of market niches within the MLP has become clearer.

Typically, innovations develop from research and development niches into socio-technical niches and then, if niche development is successful, into market niches from which they can finally - in the event of a regime shift - become strengthened into a regime-dominant technology on mainstream markets (Geels, 2011, p. 32; Schot \& Geels, 2008, pp. 539-540; Smith, Kern, Raven \& Verhees, 2014, p. 116; Smith \& Raven, 2012, p. 1025). In this case, market niches are an interim phase that radical innovations have to run through before the process of niche accumulation gives rise to replacement of the formerly dominant technology which had previously occupied mainstream markets.

In addition to their function as an interim phase, market niches can also represent permanent loci for radical innovations at the regime level. Raven (2005, p. 44), for example, describes the "development of market niches" as one of four possible development patterns for socio-technical niches. This pattern implies that niche markets develop in which a new technology is competitive in certain fields of application, though its extent remains limited and its effects on the regime usually very small. Geels (2002b) emphasises that market niches are loci where socio-technical niches can remain or develop even within stable regimes. Following his approach, new radical technologies can develop further into "small new markets". These new markets are created by new functionalities the novel technology offers, before possibly (but not necessarily) threatening the incumbent firms and replacing the dominant technology. Second, niche innovations can also be used in small market niches within existing markets, which implies that they have to compete directly and from the start with existing technologies (Geels, 2002b, p. 342). In a later version of these ideas, Geels and Schot (2007, pp. 405-412) additionally take into account the relationship between niche and (stable) regime which may be competitive or symbiotic. According to them, it is possible that socio-technical niches which have a symbiotic relationship with an existing stable regime can complement the existing regime but also give rise to modifications, without necessarily changing the regime's overall architecture ("transformation") (Geels \& Schot, 2007, pp. 406-408). Furthermore, radical niche innovations with a symbiotic relationship to the regime 
can be incorporated into it over a longer period of time, during which learning processes and ongoing improvements accumulate. This can (but likewise does not necessarily) lead to further changes to the regime architecture in situations of regime destabilisation and landscape pressure at a later time ("sequences of component innovations" that induce "reconfiguration") (Geels \& Schot, 2007, pp. 411-412).

With regard to the role of market niches within the MLP, I conclude that radical innovations can temporarily or permanently stabilise within market niches and, by this means, be incorporated into an existing socio-technical regime. Market niches are spaces where non-system-compatible, radical innovations can survive at the regime level, even for long periods. For a clear linguistic distinction, I suggest introducing the term "radical technologies" for (formerly radical) innovations which have since stabilised in a market niche. In this sense, I propose to call absorption chillers a radical technology.

To understand the relevance of these considerations for characterising absorption chiller innovations - and for innovations from market-niche technologies in general - it is necessary to take into account that talking about an innovation (the usual assumption, and not only in the MLP literature) is a generalisation. Long-term socio-technical processes of change typically include numerous incremental innovations following the initial radical innovation over time. It is these subsequent innovations that exhibit changing degrees of regime compatibility and may be perceived as incremental at a certain point in time.

Bearing these insights in mind, I suggest distinguishing between two kinds of incremental innovations within the MLP: first, improvements to the technology from within mainstream markets (i.e., from regime-dominant technologies) and, second, improvements offered by radical technologies (i.e., from market-niche technologies). Whereas the statements of the MLP are true for the first (i.e., no protection necessary), they do not necessarily apply to the latter. Unlike incremental innovations from regime-dominant technologies, incremental innovations from radical technologies indeed require protection (see section 2.1) to gain relevance. Current innovations in the field of absorption refrigeration technology can be characterised as the latter.

What we can learn from the example of absorption chiller innovations and the subsequent reflections on market niches in this section is that novelty is not a sufficient indicator for an innovation's regime compatibility and need for protection, since a reduction in novelty over time is not necessarily accompanied by an increase in regime compatibility. The example of absorption chillers can be taken to show that the mismatch between an innovation and the current regime may remain, even if the related technology can no longer be characterised as novel. With regard to the usual practice of characterising technological innovation according to the features of the initial innovation (see introduction) it can be concluded that this is not always an adequate practice.

Nevertheless, some uncertainty remains, as the finding that radical innovations can stabilise in market niches does not necessarily imply that every market-niche technology is radical. This encourages the assumption that a characterisation of innovations within the MLP should focus not only on the criterion of novelty but also include a broader range of criteria. Regime compatibility should be understood as a discrete aspect, and criteria should address the aspect of 
regime compatibility in a more direct and nuanced way. In the following I suggest a typing for this purpose worked out by Fichter and Clausen (2013) which is based on diffusion theory.

\section{Refining current typing of innovations within the MLP through diffusion-relevant aspects}

Fichter and Clausen (2013) have worked out a typing of innovations focusing on typical diffusion patterns of sustainability innovations, which seems to offer a reasonable starting point. This typing can be useful for our purposes, because it includes several influencing factors and can therefore connect the innovation's characteristics with the regime environment and as a result ease the assessment of its regime compatibility and need for protection.

\subsection{Diffusion types of innovations}

Based on an empirical analysis of 100 "diffusion cases" Fichter and Clausen (2013) suggest that the following seven main factors, which cluster known factors of influence from diffusion theory, can lead to differences in the diffusion chances and pathways as well as velocities of diffusion processes:

- market power of established suppliers,

- political push and pull,

- influence of pioneers,

- incentives to buy,

- consistency with routines on supplier and adopter sides,

- prices and economic efficiency, and

- transparency of an innovation.

Subsequently, they define five "diffusion types" of innovations representing specific combinations of these factors:

1. Capital goods of established suppliers, enhancing energy efficiency (e.g. energy-efficient servers);

2. Transparent consumer goods with enhanced characteristics (e.g. energy-efficient washing machines, organic cotton);

3. Promoted capital goods of "green" pioneer suppliers (e.g. wind and water power, combined heat and power plants);

4. Basic innovations with high demand for behavioural changes (e.g. bioenergy villages, electric cars); and

5. Complex products with unclear or long-term benefit (e.g. long-term thermal energy storage units) (Fichter \& Clausen, 2013, pp. 236-249). 
The five innovation types differ with regard to their diffusion dynamics in characteristic ways: innovations of types 1 and 2 feature high diffusion dynamics and can achieve strong market shares in a relatively short period of time ( 5 to 10 years), as they offer improvements to established, widely used investment (1) or consumption (2) goods. These types of innovations are wellknown to adopters, developed and introduced by established suppliers; they have relatively short amortisation periods and show high profitability - factors which allow for their relatively smooth integration within the existing system. Innovation types 3, 4 and 5 need considerably longer periods of time for successful diffusion - that is, until a critical mass of buyers and adopters has been reached. Typical for these types is a longer phase of stagnation at a low level, where they hardly gain any market share over a relatively long period of time (15 to 25 years or longer), demanding different, partly complex and multidimensional regime adaptations or complementary innovations to an increasing extent. Key characteristics of type 3 innovations are their high degree of innovation, uncertainties on the adopter side, importance of pioneering companies, lack of established distribution channels and a resistance on the part of established firms. In cases of type 4, a critical mass of adopters is achieved very late or not at all, especially due to necessary changes of behaviour on the adopter side, the large involvement of new enterprises and difficulties in constituting necessary new routines. Type 5 innovations have the lowest diffusion dynamic of all types, and the probability of their success is the most unclear, due to factors such as high complexity, low consistency with routines, high degree of interrelated uncertainties, relative lack of political support and unclear future prospects (Fichter \& Clausen, 2013, pp. 239-259).

\subsection{Reconsidering current absorption chiller innovations within this fra- mework}

As Fichter and Clausen (2013, p. 237) point out, this typology describes ideal types of innovations and diffusion paths, in relation to which real-world cases may differ. Also, the possibility of intervention can result in alternative path developments with respect to the described diffusion paths (Fichter \& Clausen, 2013, p. 249). However, this typing can be useful for our purposes, because it includes several factors of influence and, therefore, connects the innovation with the systemic environment within which it arises.

Referring to the seven main factors of influence on diffusion types identified by Fichter and Clausen, absorption chiller innovations feature the following characteristics:

Transparency of the innovation: Absorption refrigeration innovations are very complex technological solutions due, for example, to the numerous components of refrigeration systems (and their several possible variations) and related interdependencies, such as operating-power requirements.

Incentive to buy: The investment costs of absorption chillers are still higher than those of compression chillers, leading to the lack of a price incentive to buy. As the energy efficiency of absorption-based refrigeration systems is yet to be proved, their advantages over compression chillers are not yet clear. In addition, the future role of absorption refrigeration in the refrigeration supply regime is unclear.

Price and economic efficiency: Purchase costs for absorption cooling technologies are not yet on 
the same level as compression cooling technologies. Operating costs vary and are case specific. For most applications, an economic benefit is not immediately apparent or can be achieved only under certain circumstances (like availability of free heat sources). Future developments are difficult to predict. Due to currently high purchase costs and unclear or relatively few advantages regarding energy and cost efficiency, absorption cooling can be expected to be profitable - if at all - only in the long term.

Consistency with routines: The technical, institutional and/or cultural connectivity of absorption refrigeration innovations is limited by the need for (cheap or free) heat sources. Due to the high complexity of the technology, the availability of new heat sources (providing fluctuating heat) and the need for energy-efficient adjustment within building service engineering, the routines of engineering firms running the overall planning and the implementation of refrigeration systems need to change. This also requires enhanced competencies. As most investors still focus on purchase costs and neglect operating costs, routines in procurement have to change. Dependence on long-term payback periods combined with uncertainties regarding cost effectiveness are hindering trouble-free diffusion and integration of absorption refrigeration innovations into the existing regime.

Market power of established suppliers: The established, economically strong manufacturers of refrigeration technologies tend to focus on compression technology and, therefore, have little interest in promoting absorption refrigeration.

Influence of pioneers: The existing start-ups have low market power and reputation. The development of economically strong providers that exclusively manufacture absorption chillers has stagnated.

Political push and pull: Political push and pull has increased during the last years. However, current support and promotion is not particularly focused on absorption chillers but rather on energy-efficient solutions in general. Thus it is not clear to what extent political activities will benefit absorption refrigeration innovations.

Based on this analysis, absorption refrigeration innovations can be characterised as type 5 innovations: complex products with unclear or only long-term benefits. For our purposes here, this confirms a lack of system compatibility and a substantial need for protection.

\subsection{Discussion}

The example of absorption chillers clearly shows that the typing of innovations by seven diffusionrelevant aspects identified by Fichter and Clausen allows for a markedly more differentiated characterisation of innovations than the mere distinction between incremental and radical innovations according to the novelty criterion used by the MLP. It allows characterising innovations independently from the newness of the respective technology, and from the location of the considered innovation (at the regime level, in a socio-technical niche or in a market niche). Regime compatibility and need for protection can be identified independently from the criterion of novelty.

At the same time, the five types identified by Fichter and Clausen are able to take into account the 
distinction between radical and incremental innovations, which in this typology is extended by two subtypes of incremental and three subtypes of radical innovations. Diffusion-relevant factors related to innovation types 1 and 2 allow a relatively smooth integration within the existing system; these are incremental innovations from regime-dominant technologies. In contrast, type 3,4 , and 5 innovations feature radical characteristics or characteristics of incremental innovations from radical technologies, but with important differences concerning characteristics, barriers, dynamics and (increasing) need for protection.

Moreover, the classification scheme offered by Fichter and Clausen is connected with statements on tendencies regarding diffusion velocities related to the specific characteristics of each type of innovation. Thus, these aspects are most likely relevant for possible patterns of regime development and can contribute to further differentiation of these patterns, complementing those aspects of "stability of regime" and "relationship between existing and challenging technology" that Geels, Shot, Raven and others (see section 4) refer to. Interesting variables appear, for example, to be the kind of technology (capital or investment goods/consumer goods), complexity and transparency/comprehensibility of the particular technology, and those actors (established suppliers/pioneer suppliers) introducing an innovation. These aspects, though addressed by the MLP, have not yet been considered as relevant for possible patterns of regime change.

\section{Conclusions}

The changing character of innovations and related difficulties with their characterisation is a well-known challenge. New technologies are not developed all at once into their final form but, rather, pass through a long process, including several changes in design and functionality (Konrad \& Nill, 2001, p. 28).

This article has discussed the advantages of combining both the multi-level perspective and a classification of innovations based on empirical results from diffusion research for characterisation of innovations with regime-changing potential and the need for regime changes as a precondition for their further diffusion (radical innovations). The example of absorption chiller innovations demonstrates why and in which way this combination can be fruitful.

Application of the MLP requires clear classification of innovations as being radical in order to evaluate whether the MLP is able to provide an adequate framework for analysis. (If a considered innovation is incremental and its dissemination does not require or push more than merely smaller regime adaptations, it is not necessary to include the interplay with systemic change in such a prominent and elaborated way the MLP suggests, as no socio-technical niche is necessary to protect incremental innovations from regime conditions.) The example of absorption chiller innovations, refining a market-niche technology, shows that the novelty focused on by the MLP is not always a sufficient criterion for system (in-)compatibility. This analysis has revealed that these innovations combine characteristics of radical and incremental innovations. Concerning the causes, I argue that these have been the result of neglecting the possibly changing character of (subsequent) innovations in time within the MLP, a fact which is of essential importance for innovative refinements (or incremental innovations) from market-niche technologies. 
I therefore conclude that it is reasonable to distinguish incremental innovations within regimedominant technologies from those of established market-niche technologies. I have suggested considering the latter as improvements of non-regime-compatible, radical technologies which perpetuate the radical character of the technology (or formerly radical innovation) they refine and do not fit the characterisation of incremental innovations generally accepted by researchers using the MLP. If it is socially desirable that they gain higher relevance within the mainstream markets of a socio-technical regime, these innovations should be treated as radical-type innovations requiring a high degree of protection, be it political support in the form of funding or regulation or new supporting actors and actor networks (see section 2.1).

However, the market-niche status of a technology appears to be a helpful but insufficient indicator for an innovation's character. To avoid unreasonable reverse, further criteria are needed to operationalise this aspect in a more direct way so that it becomes possible to assess the respective need for protection independently from the criterion of novelty. Classification of innovations based on diffusion-relevant criteria seems to offer a promising perspective for this purpose. Its application to innovations in the field of absorption chiller technologies suggests that a systematic orientation towards such criteria can facilitate characterisation of such innovations in a markedly more differentiated way than offered by mere orientation towards the criterion of novelty. Operationalised by the criteria "price and economic efficiency", "consistency with routines", "market power of established suppliers", "influence of pioneers" and "political push and pull" (and associated sub-criteria), the dimension of regime compatibility, which is an essential point of interest for the MLP, emerges clearly.

As the results and conclusions drawn in this paper have been based on one example study, supplementary analyses of further examples are necessary to put them on a stronger footing.

Nevertheless, the example of absorption chillers shows that especially the case of innovations from long existing market-niche technologies seems worth considering in a more in-depth manner. In addition to regime/niche interactions the MLP focuses on, interactions between (radical) market-niche (technology) and derived innovations (in socio-technical niches) may have substantial impact on diffusion patterns and the potential degree of related regime change. It may be intriguing to pursue the issue of whether and to what extent long-term stabilisation in market niches affects the probability of larger regime changes. Specific barriers could for example result from experiences within the market niche, consolidated expectations and beliefs of actor groups, or the presence and nature of structures that support the established market-niche status of the technology.

It is especially important to examine more closely the interactions in the triangle of socio-technical regimes, market niches and socio-technical niches with incremental innovations from radical technologies (see section 4) and their implications for possible patterns of regime development. It not only seems probable that innovations that take a long time to develop and come to fruition require special political promotion to gain higher market share, but closer examination of impacts on possible patterns of regime development should lead to progressive insights. As the MLP is frequently used in sustainability research which is mostly practice-oriented, this will be useful for research and practice as well. 


\section{References}

Aizstrauta, D., Ginters, E., \& Eroles, M.-A. P. (2015). Applying Theory of Diffusion of Innovations to Evaluate Technology Acceptance and Sustainability. Procedia Computer Science, 43, $69-77$.

Albers, J., Kühn, A., Petersen, S., \& Ziegler, F. (2011). Development and Progress in Solar Cooling Technologies with Sorption Systems. Chemie Ingenieur Technik, 83(11), 1853-1863.

Becker, M. (2006/2007). Energieeffiziente Kältetechnik: Stellenwert der Automatisierungstechnik für einen energieeffizienten Betrieb sowie optimierte Betriebsführung von Kälteanlagen. Fachjournal - Fachzeitschrift für Erneuerbare Energien und Technische Gebäudeausrüstung, $6-14$.

Berliner Energie Agentur. (2009). Summerheat - Meeting cooling demands in Summer by applying HEAT from cogeneration. EU-Projektreport. Berlin. Accessed April 2019:

https://ec.europa.eu/energy/intelligent/projects/sites/ieeprojects/files/projects/documents/summerheat_publishable_final_report_en.pdf

BMWi. (2015). Förderdatenbank: Klimaschutzinitiative - Maßnahmen an Kälte- und Klimaanlagen in Unternehmen. Accessed April 2019:

http://www.foerderdatenbank.de/Foerder-

DB/Navigation/Foerderrecherche/suche.html?get=views;document\&doc=10155\&typ $=$ RL

Clausen, J. (2007). Zukunftsmarkt Solares Kühlen. Fallstudie im Auftrag des Umweltbundesamtes. Accessed April 2019:

http://www.isi.fraunhofer.de/isi-wAssets/docs/n/de/publikationen/Zukunftsmarkt

_Solares-Kuehlen.pdf

Clausen, J. (2014). Neue Ansätze in der Kälteerzeugung: Absorptionskältemaschinen und Rückkühlung mit Umgebungskälte. Accessed April 2019:

http://www.energiekonsens.de/cms/upload/Downloads/Vortraege/

Downloads_und_Publikationen/Vortrag_Clausen_140211.pdf

Clausen, J., Fichter, K., \& Winter, W. (2011). Theoretische Grundlagen für die Erklärung von Diffusionsverläufen von Nachhaltigkeitsinnovationen. Grundlagenstudie. Berlin.

Cox, S. (2012). Cooling a Warming Planet: A Global Air Conditioning Surge. Accessed April 2019:

https://e360.yale.edu/features/cooling_a_warming_planet_a_global_air_conditioning_surge

Davis, L. (2015). Air conditioning and global energy demand. Accessed April 2019:

https://energyathaas.wordpress.com/2015/04/27/air-conditioning-and-global-energy-demand/

Dibra, M. (2015). Rogers Theory on Diffusion of Innovation - The Most Appropriate Theoretical Model in the Study of Factors Influencing the Integration of Sustainability in Tourism Businesses. Procedia - Social and Behavioral Sciences, 195, 1453-1462.

Dittmann, A., Dittman, L., Seifert, J., \& Wirths, A. (2014). Absorptionskälteanlagen für die 
Gebäudekühlung mit Fernwärme: Chancen und Grenzen. Teil 2. EuroHeat\&̧Power, 43(5), $32-35$

Eicker, U. (2011). Technologien und Betriebserfahrungen mit solarer Kühlung im Nichtwohnungsbau. KI Kälte Luft Klimatechnik, 47(11), 16-19.

Eicker, U. (2012). Solare Technologien für Gebäude: Grundlagen und Praxisbeispiele (2., vollst. überarb. Aufl). Wiesbaden: Vieweg + Teubner.

Fichter, K., \& Clausen, J. (2013). Erfolg und Scheitern "grüner" Innovationen: Warum einige Nachhaltigkeitsinnovationen am Markt erfolgreich sind und andere nicht. Marburg: Metropolis.

Fichter, K., \& Clausen, J. (2016). Diffusion Dynamics of Sustainable Innovation - Insights on Diffusion Patterns Based on the Analysis of 100 Sustainable Product and Service Innovations. Journal of Innovation Management, 4 (2), 30-67.

Förster, H. (2013). Neue Generation von Absorptionskälteanlagen. KI Kälte Luft Klimatechnik, 49(01-2/2013), 12-16.

Garcia, R., \& Calantone, R. (2002). A critical look at technological innovation typology and innovativeness terminology: a literature review. Journal of Product Innovation Management, 19(2), 110-132.

Geels, F. W. (2002). Technological Transitions as Evolutionary Reconfiguration Processes: A Multi-Level Perspective and a Case-Study. Research Policy, 31 (8-9), 1257-1274.

Geels, F. W. (2004). From sectoral systems of innovation to socio-technical systems: Insights about dynamics and change from sociology and institutional theory. Research Policy, 33, 897-920.

Geels, F. W. (2007). Transformations of Large Technical Systems: A Multilevel Analysis of the Dutch Highway System (1950-2000). Science, Technology \&3 Human Values, 32(2), 123-149.

Geels, F. W. (2011). The multi-level perspective on sustainability transitions: Responses to seven criticisms. Environmental Innovation and Societal Transitions, 1(1), 24-40.

Geels, F. W., \& Schot, J. (2007). Typology of sociotechnical transition pathways. Research Policy, 36 (3), 399-417.

Heinrich, C., Wittig, S., Albring, P., Richter, L., \& Safarik, M. (2014). Nachhaltige Kälteversorgung in Deutschland an den Beispielen Gebäudeklimatisierung und Industrie. Studie im Auftrag des Bundesumweltamtes. Dessau-Roßlau.

Hellström, T. (2007). Dimensions of environmentally sustainable innovation: the structure of eco-innovation concepts. Sustainable Development, 15(3), 148-159.

Henning, H.-M., Ragwitz, M., Bürger, V., Jochem, E., Kranzl, L., \& Schulz, W. (2012a). Erarbeitung einer Integrierten Wärme- und Kältestrategie: Arbeitspaket 1 - Bestandsaufnahme und Strukturierung des Wärme- und Kältebereichs. Bonn. Accessed April 2019:

http://www.erneuerbare-energien.de/fileadmin/

Daten_EE/Dokumente__PDFs_/WuK-AP1-Abschlussbericht_BMUFormat_bf.pdf 
Henning, H.-M., Ragwitz, M., Bürger, V., Jochem, E., Kranzl, L., \& Schulz, W. (2012b). Erarbeitung einer Integrierten Wärme- und Kältestrategie: Arbeitspaket 2 - Bestandsaufnahme und Strukturierung der Akteure des Wärme- und Kältebereichs. Berlin, Bonn. Accessed April 2019: http://www.erneuerbare-energien.de/fileadmin/

Daten_EE/Dokumente__PDFs_/WuK-AP2-Abschlussbericht_BMUFormat_bf.pdf

Henning, H.-M., Ragwitz, M., Bürger, V., Jochem, E., Kranzl, L., \& Schulz, W. (2012c). Erarbeitung einer Integrierten Wärme- und Kältestrategie: Arbeitspaket 4 - Darstellung des aktuellen Rechts- und Förderrahmens und dessen Wirkungen. Bonn. Accessed April 2019:

http://www.erneuerbare-energien.de/fileadmin/

Daten_EE/Dokumente__PDFs_/WuK-AP4-Abschlussbericht_BMU_Format_bf.pdf

Holtz, G., Brugnach, M., \& Pahl-Wostl, C. (2008). Specifying "Regime" - A Framework for Defining and Describing Regimes in Transition Research. Technological Forecasting and Social Change, 75(5), 623-643.

Hoogma, R., Kemp, R., Shot, J., \& Truffer, B. (2002). Experimenting for sustainable transport: the approach of strategic niche management. London, New York: Spon Press.

Jakob, U. (2012). Solare Kühlung: Eine Alternative zu herkömmlichen Kältemaschinen. Energy 2.0, 152-156.

Karakaya, E., Hidalgo, A., \& Nuur, C. (2014). Diffusion of eco-innovations: A review. Renewable and Sustainable Energy Reviews, 33, 392-399.

Karnowski, V. (2017). Diffusionstheorie (2., aktualisierte Auflage). Baden-Baden: Nomos.

Kemp, R. (1996). The Transition from Hydrocarbons: The Issues for Policy. In S. Faucheux, D. W. Pearce, \& J. L. R. Proops (eds.), New horizons in environmental economics. Models of sustainable development (pp. 151-175). Cheltenham: Edward Elgar.

Kemp, R., Rip, A., \& Schot, J. (2001). Constructing transition paths through the management of niches. In R. Garud \& P. Karnøe (eds.), Path dependence and creation (pp. 269-299). Mahwah: Lawrence Erlbaum Associates.

Kemp, R., Schot, J., \& Hoogma, R. (1998). Regime Shifts to Sustainability through Processes of Niche Formation: The Approach of Strategic Niche Management. Technology Analysis 83 Strategic Management, 10(2), 175-195.

Konrad, W., \& Nill, J. (2001). Innovationen für Nachhaltigkeit: Ein interdisziplinärer Beitrag zur konzeptionellen Klärung aus wirtschafts- und sozialwissenschaftlicher Perspektive (Schriftenreihe des IÖW No. 157/01). Accessed April 2019:

http://www.ioew.de/fileadmin/

_migrated/tx_ukioewdb/IOEW_SR_157_Innovationen_fuer_nachhaltigkeit.pdf

Kranzl, L., Hummel, M., Matzenberger, J., Müller, A., Toleikyte, A., Totschnig, G., . . Neusser, M. (2014). Power through Resilience of Energy Systems: Energy Crises, Trends and Climate Change (PRESENCE). Final report. Vienna. Accessed April 2019:

http://www.eeg.tuwien.ac.at/eeg.tuwien.ac.at_pages/research/downloads/ PR_356_B068675_PRESENCE_FinalPublishableReport_submitted.pdf 
Levidow, L., \& Upham, P. (2017). Linking the multi-level perspective with social representations theory: Gasifiers as a niche innovation reinforcing the energy-from-waste (EfW) regime. Technological Forecasting and Social Change, 120, 1-13.

Osunmuyiwa, O., Biermann, F., \& Kalfagianni, A. (2017). Applying the multi-level perspective on socio-technical transitions to rentier states: The case of renewable energy transitions in Nigeria. Journal of Environmental Policy 85 Planning, 9(4), 1-14.

Petersen, S., Albers, J., Hennrich, C., Hunt, S., Hüls, W., Lanser, W., \& Schröder, M. (2013). Absorptionskälteanlagen für die Gebäudekühlung mit Fernwärme: Projektergebnisse aus EnEff Wärme. EuroHeat\&Power, 43(5), 42-49.

Raven, R. P. J. M. (2005). Strategic Niche Management for Biomass: A Comparative Study on the Experimental Introduction of Bioenergy Technologies in the Netherlands and Denmark (Dissertation). Technische Universität Eindhoven.

Raven, R. P. J. M., Heiskanen, E., Lovio, R., Hodson, M., \& Brohmann, B. (2007). The Contribution of Local Experiments and Negotiation Processes to Field-Level Learning in Emerging (Niche) Technologies: Meta-Analysis of 27 New Energy Projects in Europe. Paper submitted for the special issue of the Bulletin of Science, Technology \& Society on Renewable Energy and Sustainability. Accessed April 2019:

http://www.oeko.de/oekodoc/720/2007-201-en.pdf?PHPSESSID=bcet37132hiqdnl69k4pu6cl76

Reichelt, J. (2000). Wo steht die Kältetechnik in Deutschland und weltweit? Accessed April 2019:

http://www.treffpunkt-kaelte.de/kaelte/de/html/vortrag/allgemein/reichelt.pdf

Rogers, E. M. (2003). Diffusion of innovations (5th ed.). New York: Free Press.

Rotmans, J., Kemp, R., \& van Asselt, M. (2001). More Evolution than Revolution: Transition Management in Public Policy. Foresight - the Journal of Futures Studies, Strategic Thinking and Policy, 3(1), 15-31.

Schindler, W. (2010). Wärme ist Antrieb für Kälte. Kälte Klima Aktuell, 29, 62-65.

Schmid, W. (2011a). KWK-Gesetz ist wichtigster Treiber für Absorbermarkt: Wachstumsmarkt Absorptionskältemaschinen. EuroHeatÉPower, pp. 12-13.

Schmid, W. (2011b). Nachhaltige Kälteerzeugung durch Fernwärme-angetriebene Absorptionskältemaschine: Hohe Auskühlung des Rücklaufs. EuroHeatEYPower, 40 (6), 42-45.

Sivak, M. (2013). Will AC Put a Chill on the Global Energy Supply? American Scientist, $101(5), 330$.

Smith, A., \& Raven, R. P. J. M. (2011). What is protective space? Reconsidering niches in transitions to sustainability (Working Paper 11.05). Eindhoven University of Technology, Eindhoven. Retrieved from: http://alexandria.tue.nl/repository/books/729198.pdf

Wainstein, M. E., \& Bumpus, A. G. (2016). Business models as drivers of the low carbon power system transition. A multi-level perspective. Journal of Cleaner Production, 126, 572-585. 
Xi, H., Luo, L., \& Fraisse, G. (2007). Development and applications of solar-based thermoelectric technologies. Renewable and Sustainable Energy Reviews, 11(5), 923-936.

Yang, K.-P., Chou, C., \& Chiu, Y.-J. (2014). How unlearning affects radical innovation: The dynamics of social capital and slack resources. Technological Forecasting and Social Change, 87, $152-163$.

Ziegler, F. (1997). Sorptionswärmepumpen. Habilitationsschrift. Forschungsberichte des Deutschen Kälte- und Klimatechnischen Vereins: Vol. 5\%. Stuttgart. 


\section{Biographies}

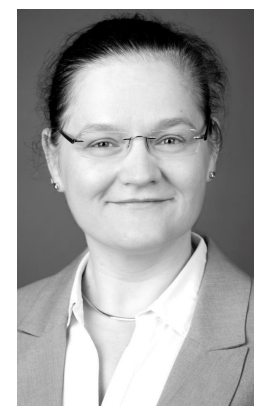

Dorothee Keppler. Dorothee Keppler is a Research Associate and Head of the Research Area "Climate and Energy" with the Center for Technology and Society, Technische Universität Berlin, Germany. She holds a diploma and a PhD in planning sciences. In her doctoral thesis she examined possibilities and limits of regional players to promote renewable energies in German mining regions, combining approaches from sociology of technology and regional science. Since almost twenty years she has been working as a social scientist, often in interand transdisciplinary research projects. Her research focuses on the societal dimension of the German "energy turnaround", including interdependencies of innovations and socio-technical transitions in the energy sectors, regional and local (renewable) energy governance, and citizens' and stakeholder participation. Up to now she has authored more than forty articles, books, chapters and papers and was co-editor of three books.

\section{ISSN 2183-0606}

http://www.open-jim.org

http://creativecommons.org/licenses/by/3.0 